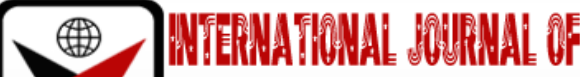

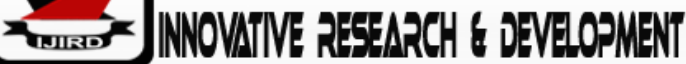

ISSN 2278-0211 (Online)

\section{Examining the Level of Illegal Water Consumption in High- and Low-Density Estates of Kisumu City, Kenya}

\author{
Teresa Aoko Onyango \\ Graduate Student, Department of Environmental Planning and Management \\ Rongo University, Migori County, Kenya
}

\begin{abstract}
:
Water utilities around the world experience varying degrees of water loss and although there has been significant steps towards reducing it, water losses still occur often as a result of poor infrastructure which cause pipe bursts/leakages, lack of proper planning, water theft, illegal consumption and water meter irregularities. Illegal water consumption is rampant where the consumers have a negative attitude towards the water service providers mainly because of the belief that they are paying for a resource that is abundant and free in nature. The International Water Association classifies illegal consumption under commercial or apparent losses because the water is beilieved to have reached the consumer but it can not be accounted for and hence does not contribute to the water utilities' revenue. Cross-sectional survey was used to investigate the level of non-revenue water in Kisumu city's high and low density estates using Manyatta and Milimani as a represenation of each estate respectively. The survey targetted 384 households out of which 362 were interviewed.Primary data was also collected through Focused Group and supplemented with secondary of desk review from KIWASCO's reports. The data collected was subjected to descriptive analysis and presented using frequencies and percentages.An Analysis of the data collected revealed that 31.7\% and 26.8\% of households in Manyatta and Milimani consumed water illegally through unmettered connections respectively, a further $28.9 \%$ of the respondents in Manyatta consumed water illegally through illegal reconnection after their water had been disconnected while this was represented by $30 \%$ in Milimani estate which is a clear indication that consumers in low desnity estates also consume water illegally contrary to what most people believe. 4 out of the 5 illegal water consumption determinants used by the researcher however indicated that the level of illegal consumption is higher in high density areas than low density areas by an average of 4.9\% but also, it is evident the percentage is higher in the two estates than the recommended 25\%. The paper therefore recommends that assumptions should not be made that there are no cases of illegal water use in low density areas if the water utility is to realize its goal of reducing non-revenue water loss to acceptable levels because these areas contribute to nonrevenue water loss just as much as the high-density areas and even though the number of illegal use maybe low but the intensity may surpass that of high density neighborhoods.
\end{abstract}

Keywords:Non revenue water, illegall water consumption, high density estates, low density estates

\section{Introduction}

Illegal consumption can occur whether the consumer is a registered water user or not where registered users intentionally tamper with their meters by either reversing, by-passing it or introducing impurities to reduce efficiency of the meters and unregistered users illegally connecting themselves to the distibtion system. It is often assumed that illegal water consumption only occurs in high density areas not in low density areas or even if they do the levels may be somewhat insignificant and therefore establishing the difference in illegal consumption in the two study areas is important in making comparisons used draw conclusions on the research problem and refuting or backing up these claims.

\subsection{Illegal Consumption as a Component of Non-Revenue Water}

The International Water Association designed a water balance to help in understanding the complexity of nonrevenue water and reduce water loss in water utilities across the world. The water balance was also a unanimous action plan to reduce confusion and the varying definations and issues surrounding unaccounted for water. Illegal or unauthorized consumption is classified under apparent/ commercial losses. When the water utilities put water into their system there are always two outcomes, an authrorised consumption (Billed or unbilled) that generates revenue or water losses which can either be real/physical due to overflow of utility's storage tanks, leakage during transmission and pipe bursts or apparent/commercial due to metering inaccuracies or unauthorized consumption otherwise known as illegal water consumption. 


\subsection{Literature Review on Illegal Water Consumption}

Efficient and equitable production and provision of water resource is the major purpose of water utilities around the world and according to UN, Habitat (2012), these services should be provided within legal bounds and agreements that ensure frequent audits to gauge the performance of the water utilities in water resources management and it's related challenges. Some of the challenges faced by water utilities as stated by Rizzo (2008) include illegal water consumption also known as water theft where consumers come up with new and challenging ways to consume water illegally and therefore makes the problem very difficult to solve. These sentiments are echoed by a research done by Butler and Memon (2006) who argued that illegal water consumption not only limits the ability of water utilities to operate efficiently but also cause the loss of water in the supply system. They further stated that illegal consumption is where consumers deliberatelty bypass water meters to get water without paying for the services and also stated the causes of illegal water consumption as water shortage or scarcity, poor management, lack of consumer awareness, high tariff rates and delayed water connection for individuals who have applied for those services. According to Hailu et al (2011), one of the reasons why measures put in place to reduce illegal consumption have proven to be futile is because majority of the consumers who use water illegally are of the basic assumption that it is a basic human right and therefore should not be charged which is sometimes a slogan of most politicians who want to earn the consumers support at the expense of sustainability. Further, the findings of a survey done by Hailu et al (2011) indicated that $62 \%$ of small scale water providers(vendors) had legal connection to the water utility network while the remainining 38\% percent sold water illegally, where $24 \%$ of those were cases where connections were made illegally from someone else's piped connection while $11 \%$ connected themselves directly to the main distribution system.

UN Habitat (2012) decribes illegal consumption as unauthorized water use and classifies it as meter by-passing, illegal connection, fetching water at a pint before the meter, meter reversal and meter tampering. A further description by UN-Habitat of these categories of illegal water use defines Meter by-pass as a situation where the consumers with a meter has an alternative pipe taping before the meter which is directly conneted to the house, the roof tank or garden, illegal connection is defined as the situation where the consumer is not even a registered client of the water service providers but have simply connected themselves to the distribution network, illegal reconnection is where the customer has been disconnected by the water service providers due to cases such as non-payment and they just reconnect themselves to the distribution network without meeting the required guidelines provided, fetching water at a point before the meter that is not recorded by the meter by closing the stop cork and removing the meter and connecting a pipe to the ntwork to fetch water then returning the meter hence the amount of water fetched is not accounted for by the meter, meter reversal is where the consumers installs the meter in reverse or reversing the meter manually so that it counts backwards to desired readings and meter tampering is decribed by the UN-Habitat (2012) as a situation where the consumers intentionally corrupts the meters by reducing or distorting mechanical gears, boiling the meter to melt internal components or introducing impurities to reduce the efficiency of the meter.

These cases of ilegal water consumption are more rampant in the informal settlements which Hailu et al 2011 explains that is because of the intermittent water supply experienced in these areas which makes the consumers to store water while anticipating the next supply while some might even seek water from the cartels who take charge of water provision in the slums illegally, while some households will decide to seek alternative ways on how they can access the water even through illegal feeds off the main distribution channel thereby contributing to the level of unaccounted for water. These findings were further supported by reports of the UN HABITAT (2015) which stated that there is inadequate service provision of utilities in informal settlements owing to the fact that utility provision in these areas may require high capital investments that may realize less returns and therefore water utilities may prefer to invest in the provision of services to more formal urban communities. The nature of illegal water consumption is often complex to understand and therefore the management of this water resource requires approaches that include all the stakeholders involved UNHABITAT (2015) especially the consumers because public participation would ensure that the public is aware of the offences and their related penalties and why to avoid the culture of resentment towards water utilities

\section{Materials and Methods}

This section provides details on the study area, methods and materials used in data collection, the research design, calculation of the sample size and analysis techniques that were adopted by the researcher.

\subsection{Study Area}

Kisumu City is located in the Nyanza province of Kenya along the Lake Victoria Shores. The city covers a total area of 417 sq. km, of which 297 sq. km is land, and 120 sq. km is water mass. Kisumu is the principal city of western Kenya and is the third-largest city in Kenya after Nairobi and Mombasa. Kisumu County has a shoreline on Lake Victoria occupying parts of the northern, western and southern shores of the Winam Gulf and is situated on the equator with a hot and humid year-round climate and an annual rainfall of approximately 1,200 mm occurring in two seasons i.e. March-May for long rains and October- December for short rains. The average temperature is between $28-35^{\circ} \mathrm{C}$ with low temperatures dropping into the $18^{\circ \mathrm{C}}$ at night. Kisumu is a metropolitan county that comprises of the main Kisumu city area, it's suburbs and satellite towns totaling to a population of 1,155,574 according to the 2019 Kenya National Census. As the third largest city the county has many educational, industrial, agricultural, medical and social facilities as well as fish farming which is fast becoming a major industry due to it being located next to one of the largest fresh water lakes making it also a fastdeveloping tourist industry. 


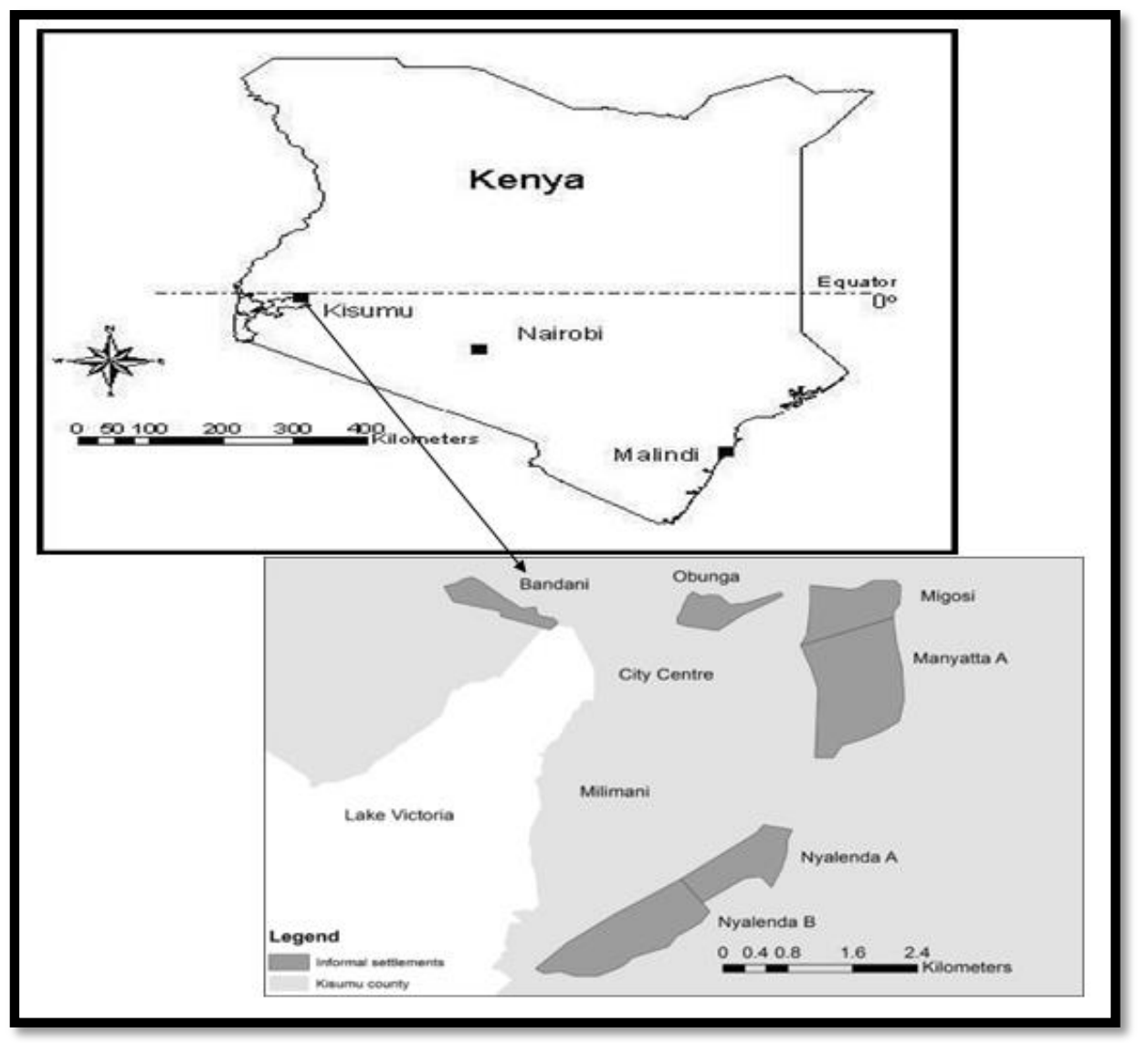

Figure 1: The Map of the Study Area

Source: Researchgate.Net, Joseph Okotto-Okotto (2015)

\subsection{Data Collection Instruments and Methods}

The study employed both qualitative and quantitative methods of data collection through questionnaires which had the first part with closed ended questions and the second part with open ended questions so that the respondents could further give their views or opinions on the research question at hand. The data collected was analyzed in the statistical package for social sciences version 24 (SPSS) and presented using tables and figures.

Kisumu has 72,000 registered water users and therefore using Cochran's formula of determination of a sample size, 384 households in both Manyatta (high density, low income) and Milimani (low density, high income) were targeted out of which 362 responses were obtained. The survey questions assessed 5 major factors that were used as determinants of illegal consumption in Kisumu, Kenya. These factors included unmetered connections, delayed water tariffs, rate of water disconnection, illegal reconnection and water meter irregularities. The study was conducted for a period of 5 months including December holidays as there was a guarantee of finding respondents in the targeted households hence the high response rate.

The exploratory study was done through a Focused Group Discussion where 16 participants were chosen on a voluntary basis. However, the participants were selected through purposive sampling to get people who are well conversant with the issue of non-revenue water.

The researcher used a two-style sampling technique that was probability and non-probability based. The probability-based sampling was used to identify the sample size and engage the households in the study. The proposed sample design for households assumed a two-stage cluster sample design which was based on a multi-stage stratified cluster sampling where the selection of the Primary Sampling Units (PSU), the Blocks/wards (clusters), formed the first stage of sampling. Selection of the Elementary Units (EU) households was the second stage of the sampling and it entailed selecting a random and systematic sample of a fixed number of households within the randomly selected blocks/ward and locating the geographic center of the cluster (block/ward).

\section{Presentation of the Results Findings}

This section contains the analysis and presentation of the responses collected and discussion of the research findings.

\subsection{Demographic Characteristics of the Respondents}

From the 362 respondents who participated in the household survey, the researcher explored a number of demographic characteristics. It was found that gender distribution was dominated by the female respondents at 234 (64.6\%) while male respondents were 128 (35.4\%). The research was conducted during the day when most males were away from the house or at work while the females remained home to take care of the household affairs which could explain the more women respondents interviewed. Also, in some cases where the male respondents were available, they 
would refer the researcher to the female respondents' saying that the women are more involved in how they obtain water and use water in the households and in most cases are given money by their husbands to pay for utility bills. An analysis of the age distribution of the respondents indicated that respondents in the 18 - 30 years' age bracket was 117 (32.3\%), those between the age brackets of 31- 40 years were 168 (46.4\%), those between the ages of 41 and 55 were 43 (13.0\%) and the respondents above 55 years of age were $26(8.3 \%)$. The respondents in the lower age bracket (18-40 years) were $78.7 \%$ and more that those who were 41 years which only constituted $21.3 \%$. This clearly depicts a normal distribution curve. The occupation of the respondents indicated that majority of the respondents were housewives. They comprised $34.8 \%$ because they were available even on the weekdays when the research was being conducted. Civil servants, business persons and other professions made up 24.03\%, $11.88 \%$ and $20.44 \%$ respectively. Farmers, the lowest in number of respondents $(8.8 \%)$ are attributable to the fact that the study was conducted in an urban center with few farmers. The study conducted in Manyatta and Milimani estates gave a good comparison on the water usage and level of illegal water consumption in both areas. The study therefore interviewed $61.87 \%$ respondents in Manyatta high density area and $38.13 \%$ in Milimani low density areas as shown in table 1

\begin{tabular}{|c|c|c|}
\hline Respondents' Characteristics & Frequency & Percentage \\
\hline $\begin{array}{c}\text { Gender } \\
\text { Male } \\
\text { Female }\end{array}$ & $\begin{array}{l}128 \\
234\end{array}$ & $\begin{array}{l}35.36 \\
64.64\end{array}$ \\
\hline $\begin{array}{c}\text { Age of the respondents' } \\
18-30 \text { years } \\
31-40 \text { years } \\
41-55 \text { years } \\
\text { Above } 55 \text { years }\end{array}$ & $\begin{array}{c}117 \\
168 \\
47 \\
30\end{array}$ & $\begin{array}{c}32.32 \\
46.41 \\
12.98 \\
8.29\end{array}$ \\
\hline $\begin{array}{c}\text { Occupation of the respondents' } \\
\text { Housewives } \\
\text { Farmers } \\
\text { Civil servants } \\
\text { Business persons } \\
\text { Other profession }\end{array}$ & $\begin{array}{c}126 \\
32 \\
87 \\
43 \\
74\end{array}$ & $\begin{array}{c}34.81 \\
8.84 \\
24.03 \\
11.88 \\
20.44\end{array}$ \\
\hline $\begin{array}{c}\text { Location of the respondents' } \\
\text { Manyatta } \\
\text { Milimani }\end{array}$ & $\begin{array}{l}224 \\
138 \\
\end{array}$ & $\begin{array}{r}61.87 \\
38.13 \\
\end{array}$ \\
\hline
\end{tabular}

Table 1: Demographic Characteristics of the Respondents

\subsection{Illegal Water Consumption in High- and Low-Density Estates on Kisumu City}

Residents of Kisumu city mainly get their water from KIWASCO which has two water treatment plants one at Dunga which extracts water from Lake Victoria and the other at the Kajulu filter which extracts water from river Kibos. Ideally water supplied by KIWASCO to consumers should be legally connected and metered. However, unmetered consumption, meter by-passing, meter tampering/vandalism, meter reversal and illegal connections which were the determinants used by the researcher to determine the level of illegal consumption in these two areas. These forms of illegal consumption are quite common and contribute to water loss in the distribution process as discussed below.

\subsubsection{Metered Legal Connection}

Metered water connections are legalized and essential for water utilities. They determine the level of water distributed into the water supply systems and is accounted for as a source of revenue for KIWASCO. According to the Kenyan Water Act (2016) metered water ensures that the water utilities are able to self-sustain themselves through the revenue collected. Therefore, this study examined legalized metered connections versus the water revenue during the past 12 months from records of KIWASCO in both Manyatta (high density) and Milimani (low density) estates. The results show that the number of respondents with metered connections for the past 12 months in Manyatta estate was $153(68.3 \%)$ out of the 224 respondents. In the case of Milimani estate it was found that 101 (73.2\%) out of the 138 respondents had metered water connections which is higher than that of Manyatta and is attributed to the fact that aside from Milimani being in close proximity with KIWASCO's main water treatment plan making it less costly to install water distribution equipment, the area also has detached residential houses making it easier to map and install KIWASCO meters.

\subsubsection{Unmetered Connections (Illegal Connections)}

The study found that although some consumers are registered water users by KIWASCO, their consumption is unmetered hence are not billed which is also considered as a form of illegal water consumption. Unmetered water consumption promotes dishonesty and uneconomical water consumption hence contributing to the increase in volumes of non-revenue water. The study found that some consumers/respondents (71 and 37 in Manyatta and Milimani respectively) have had their connections unmetered at some point in the past 12 months. According to the guidelines provided by KIWASCO, anyone whose consumption is unmetered and still gets their water from the company is consuming water illegally. Therefore, it was found that in Manyatta estate 31.7\% of the surveyed households were illegal consumers while in Milimani estate some $26.8 \%$ also consumed water illegally. Thus, the level of illegal water consumption is higher by $4.9 \%$ in the high-density estates such as Manyatta compared to the low-density estates such as Milimani. Further, 
although illegal consumption is lower (26.8\%) in the low-density estates i.e., Milimani, it is still above the $25 \%$ recommended level by WASREB. Milimani being a high-income estate and therefore the most common assumption is that they cannot consume water illegally and this is the kind of loophole that some residents have taken advantage as most of the respondents said that KIWASCO rarely does regular routine check of meters hence backing the assumption statement. Some of the respondents also pointed out the fact that they travel a lot and those they leave in charge of their homes resort to illegal ways of consuming water and electricity so as to pocket the money meant for these bills. These results were as indicated in figure 2 .

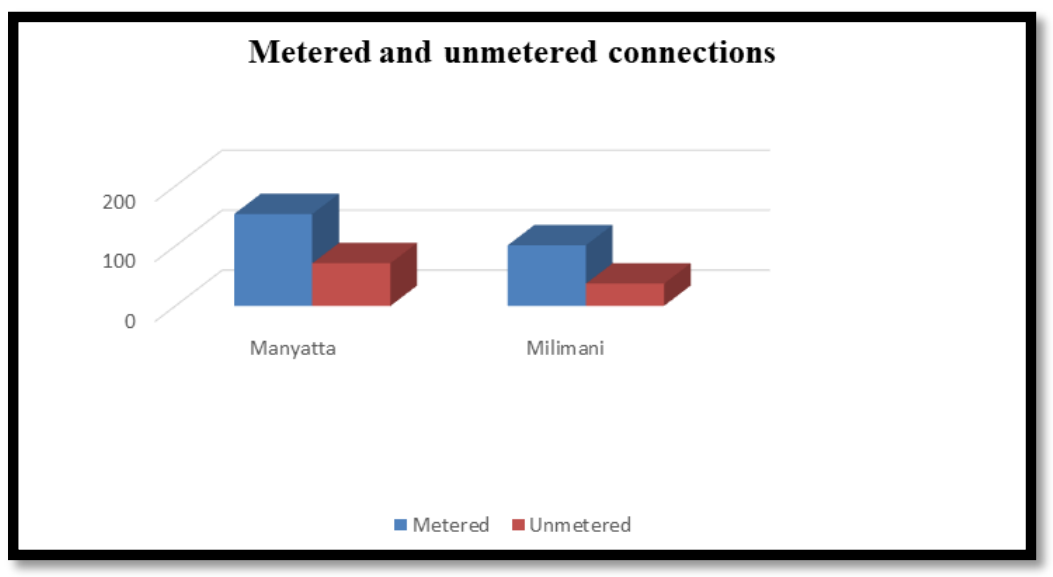

Figure 2: Connection Status of the Respondents

The results from the correlation analysis show a strong positive relationship between non-revenue water and unmetered consumption where the ( $p$-value $<0.05$ and rho=876) compared to metered consumption which had a strong negative relationship with non-revenue water (rho=-.756). This is tandem with the water balance framework drawn out by the International Water Association which categorizes metered consumption as a form of revenue water, meaning that through metered consumption, water utilities are able to collect revenue and ensure self-sustenance. Unmetered consumption on the other hand is classified under non-revenue water because the water is believed to have reached the consumer but there is no payment that accounts for its use. From this analysis it may be concluded that even though Milimani had lower cases of unmetered consumption than Manyatta, the level of illegal consumption in these two areas was still higher than that recommended by WASREB (25\%) suggesting a continued illegal water use and hence nonrevenue water. Any increase in illegal water consumption in these two estates can therefore significantly affect revenue to KIWASCO and reduce the company's efficiency and income in its operations as shown in table 2

\begin{tabular}{|c|c|c|c|}
\hline \multirow{2}{*}{ Factors } & & Non-Revenue Water & \\
\cline { 2 - 4 } & $\mathbf{N}$ & P-value & Pearson rho \\
\hline Unmetered Consumption & 362 & .000 & $.876^{* *}$ \\
\hline Metered Consumption & 362 & .000 & $-.756^{* *}$ \\
\hline
\end{tabular}

Table 2: Correlation between Metered/Unmetered Connections and NRW Loss **Correlation Is Significant at the 0.01 Level (2-Tailed)

\subsubsection{Delayed Water Tariffs}

KIWASCO accounts for the level of water consumption through the payment of water bills by the consumers mainly by monthly meter readings and billing. Unbilled consumption contributes to the level of water lost by the water utilities as it cannot be accounted for hence determined as water loss. KIWASCO considers billing beyond 2 months as illegal consumption. Therefore, during the 12-month period it was found that in Manyatta, 49.6\% of the respondents receive their bills monthly, $19.6 \%$ bi-monthly, $16.1 \%$ quarterly, $11.2 \%$ annually and $3.7 \%$ not at all. In Milimani however, $52.2 \%$ receive their water bills monthly, $21.7 \%$ bi-monthly, $15.2 \%$ quarterly, $10.2 \%$ annually and $0.7 \%$ not at all. In Manyatta therefore, $69.2 \%$ of the respondents have been consuming water legally compared to $30.8 \%$ illegally water consumers at some point in the last 12 months. Over the same period, in Milimani, 73.2\% consume water legally while $26.1 \%$ have consumed water illegally. Thus, the level of illegal water consumption is higher in high density estates such as Manyatta than in low density estates such as Milimanias indicated in figure 3. 


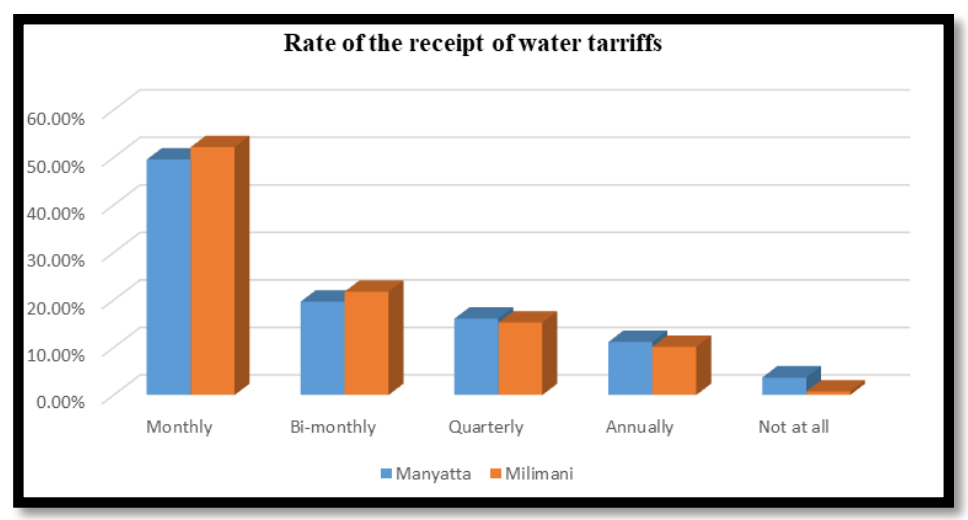

Figure 3: The Rate of Water Tariff Receipt by Respondents

The table 3 represents a correlation analysis carried out which indicated that there is a moderate relationship between delayed water tariff and non-revenue water with a p-value of 0.041 and rho $=0.238$. Delayed water tariffs though amounts to the amount of water not accounted for in that particular month it usually occurs due to omission error on the part of the water utilities and as such even the consumers who had not paid their water bills for more than three months argued that it was not their fault since they had not received their bills and therefore cannot pay KIWASCO blindly without knowing what they owed. Some on the other hand acknowledged that although their connections are legalized, they are unmetered and therefore they do not receive the bills for the water which is a form of illegal consumption hence nonrevenue water. Again, in delayed water tariffs Milimani had 26.1\% and Manyatta had 30.81\% indicating that they both contribute to non-revenue water levels and therefore an increase in this kind of illegal consumption will therefore have moderate contributions to the level of non-revenue water at KIWASCO.

\begin{tabular}{|l|c|c|c|}
\hline \multirow{2}{*}{ Delayed water tariffs } & & Non-Revenue Water & \\
\cline { 2 - 4 } & $\mathrm{N}$ & P-value & Pearson rho \\
\hline & 362 & 0.041 & $0.238^{*}$ \\
\hline
\end{tabular}

Table 3: Correlation between Delayed Water Tariffs and Non-Revenue Water

* Correlation Is Significant at the 0.01 Level (2-Tailed)

\subsubsection{Level of Water Disconnection in Manyatta and Milimani Estates, Kisumu City}

Any consumer who has had their water disconnected at some point is believed to have been consuming water illegally or involved in some illegal activities with regards to water consumption. The researcher therefore investigated the number of respondents who have had their water supply disconnected at some point in the past 12 months and the results indicated that in Manyatta, 63.0\% (141) of the respondents have not had their water disconnected in the past 12 months hence have been consuming water legally as opposed to the remaining $37.1 \%$ (83). In Millimani $71.0 \%$ (98) of respondents consume water legally while $29.0 \%$ (40) have consumed water illegally at some point in the past 12 months. Using the rate of water disconnection therefore to determine the level of illegal water consumption indicates that the level of illegal consumption is higher in the high-density areas compared to the low-density areas by $8.1 \%$. However, at $29.0 \%$ level of illegal consumption, the low-density estates are also considered to be significant contributors to the amount of water lost by KIWASCO. These findings were as indicated in table 4.

\begin{tabular}{|c|c|c|c|}
\hline Water Disconnected & Manyatta & Milimani & Total \\
\hline Yes & 83 & 40 & 123 \\
\hline No & 141 & 98 & 239 \\
\hline Total & 224 & 138 & 362 \\
\hline
\end{tabular}

Table 4: Water Disconnection Status in Milimani and

Manyatta Estates in Kisumu City

Table 5 is a representation of a correlation analysis carried out on the rate of water disconnection at KIWASCO for a period of 12 months which indicated that it also had a moderate relationship with non-revenue with a p-value of 0.000 and rho= 0.318. Although KIWASCO may disconnect water due to illegal consumption, the water can also be disconnected for reasons which may not necessarily be that the consumer was using water illegally. With the rate of water disconnection being 37.1\% in Manyatta and 29.0\% in Milimani, these results indicate that an increase in the level of this form of illegal consumption will contribute moderately to the level of non-revenue water levels at KIWASCO.

\begin{tabular}{|l|c|c|c|}
\hline \multirow{2}{*}{ Rate of Water disconnection } & & Non-Revenue Water & \\
\cline { 2 - 4 } & $\mathrm{N}$ & P-value & Pearson rho \\
\hline & 368 & .000 & $.318^{* *}$ \\
\hline
\end{tabular}

Table 5: Correlation between Water Disconnection and NRW Loss

** Correlation Is Significant at the 0.01 Level (2-Tailed) 


\subsubsection{Illegal Water Reconnection in Manyatta and Milimani Estates of Kisumu City}

Often after KIWASCO has disconnected consumer's water supply, it is reconnected after the consumer meets the necessary requirements including paying all or part of the bills. However, the study finds that some 59 (71.1\%) out of 83 respondents in Manyatta had their water legally reconnected by KIWASCO while the remaining 24 (28.9) resorted to selfreconnection. In Milimani, out of the 40 respondents who have had their water disconnected, 28 (70\%) had their water legally reconnected by KIWASCO while the other 12 (30\%) resorted to self-reconnection. During the FGD the participants stated that some illegal self-reconnections include meter tampering and meter by-passing without approval by KIWASCO. It was found that even after disconnection by KIWASCO some and of the respondents in Manyatta (28.9\%) and Milimani (30\%) continued to consume water through illegal connections. One of the discussants in the FGD at Milimani Estate argued that some of these reconnections are usually made without their knowledge. The level of illegal reconnection being higher in Milimani is attributed to the fact that there are no frequent monitoring and evaluation of these areas and as such if one does this, they can get away with it for a long period or until month end when the field technicians will be going round again to read meters and bill the consumers. Majority of the participants also expressed their concerns over the fact that KIWASCO's field technicians in most cases just disconnect the water supply without talking to the people involved. Thus, it is difficult to know whether the disconnection has been done by KIWASCO or other people who are fond of meter vandalism although one of the discussants, a former employee of KIWASCO insisted that the water utilities often give an ultimatum of 21-30 days before they disconnect the consumer's water supply and therefore cannot be blamed. Figure 4 gives the findings from this study.

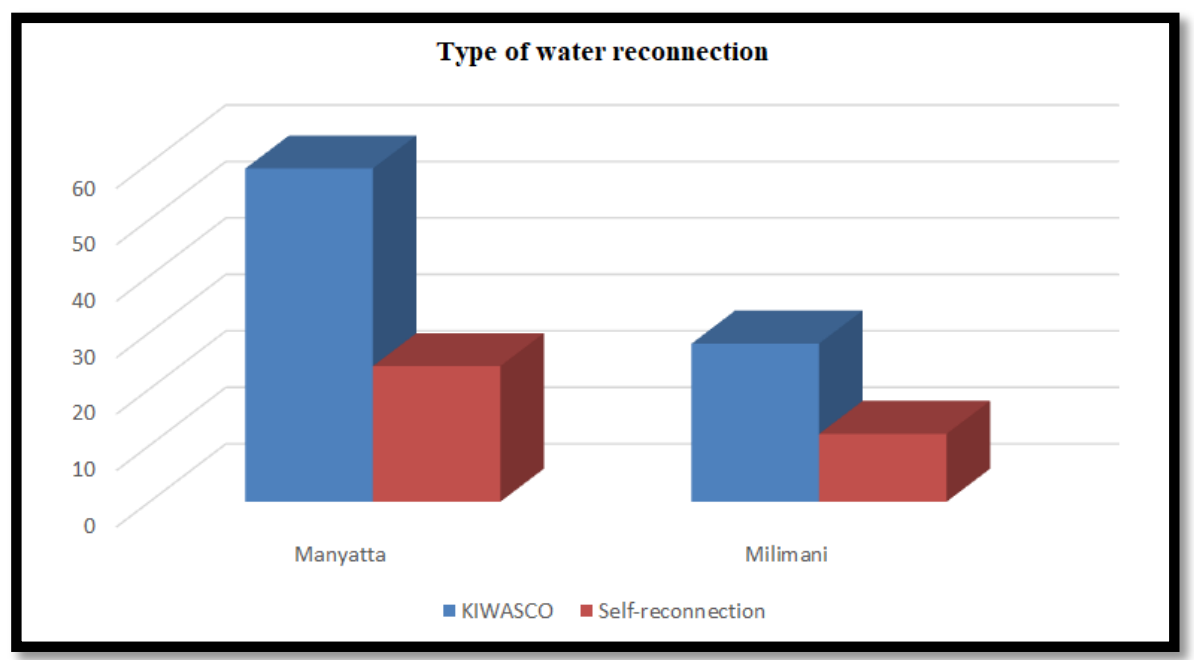

Figure 4: Type of Water Reconnection in Manyatta and Milimani Estates of Kisumu City

The study finds a strong positive correlation between illegal water reconnection and the level of non-revenue water. Therefore, an increase in the level of illegal water reconnection in these two estates will strongly contribute to the increase in the level of non-revenue water at KIWASCO because the consumers will be getting water that cannot be accounted for by KIWASCO. These results were as indicated in table 6.

\begin{tabular}{|c|c|c|c|}
\hline \multirow{2}{*}{ Illegal Water Reconnection } & & Non-Revenue Water & \\
\cline { 2 - 4 } & $\mathrm{N}$ & P-value & Pearson rho \\
\hline & 362 & .000 & $.998^{* *}$ \\
\hline
\end{tabular}

Table 6: Correlation between Illegal Water Reconnection and NRW Loss

** Correlation Is Significant at the 0.01 Level (2-Tailed)

\subsubsection{Water Meter Irregularities}

A study done by Vermersch et al (2016) indicated that apparent/commercial losses due to meter errors and metering irregularities are one of the major contributors to high level of non-revenue water loss in water utilities. UNHabitat 2012, categorizes illegal water consumption to include meter-bypassing where the consumer has an alternative pipe just before the meter directly to the house, meter reversal where the meter is set to count backwards to desired readings and meter tampering where the consumer intentionally vandalizes their meters in order to reduce its efficiency. In this study it was found that there was illegal water consumption through meter irregularities occurred among 70 out of the respondents in Manyatta estate. In this estate, some 31.3\% of the respondents agreed that they have been involved in meter irregularities either through by-passing, reversal or tampering which led to illegal water consumption and revenue loss. The remaining 68.75\% (154) have been consuming water legally. In Milimani, 37 (26.8\%) of the 138 of the respondents agreed to have been involved in meter irregularities at some point in the past 12 months and the other 73.19\% have consumed water legally. This indicated that the level of illegal water consumption through meter by-passing, reversal and tampering is higher in the high-density estates than in the low-density estates by $4.44 \%$. The respondents however argued that some of the meters installed by KIWASCO are faulty and overcharge them which leads to them 
looking for means to adjust their meters which is considered illegal as per the KIWASCO's guidelines. The results were as shown in table 7.

\begin{tabular}{|c|c|c|c|}
\hline Cases in Water Meter Irregularities & Manyatta & Milimani & Total \\
\hline Yes & 70 & 37 & 107 \\
\hline No & 154 & 101 & 255 \\
\hline Total & 224 & 138 & 362 \\
\hline
\end{tabular}

Table 7: Cases Where There Have Been Water Meter Irregularities

Table 8 shows a correlation analysis carried out which indicated that water meter inaccuracies have strong significant contributions to the level of non-revenue water loss. With Milimani at $26.81 \%$ and Manyatta at $31.25 \%$, these results indicate that an increase in this kind of illegal consumptions in these two areas will causes significant loss due to non-revenue water at KIWASCO.

\begin{tabular}{|l|c|c|c|}
\hline \multirow{2}{*}{ Water Meter Inaccuracies } & & Non-Revenue Water & \\
\cline { 2 - 4 } & $\mathrm{N}$ & P-value & Pearson rho \\
\hline & 362 & .000 & $.872^{* *}$ \\
\hline
\end{tabular}

Table 8: Correlation between Water Meter Irregularities and NRW Loss

** Correlation Is Significant at the 0.01 Level (2-Tailed)

\subsection{Discussion on Illegal Water Consumption in High- and Low-Density Estates of Kisumu}

While illegal consumption can differ from one utility to another, the five forms discussed above which are unmetered consumption, delayed water tar iffs, water disconnection, illegal water reconnection and meter irregularities are the most common and contribute to $92 \%$ of illegal water use at KIWASCO, Kisumu City. Of the 5 illegal consumption determinants, 4 were found to be higher in the high-density estates compared to the low-density estates and on average, the level of illegal consumption was found to be higher in the high-density areas by $4.9 \%$ backing up the notion that there is a positive relationship between low income and illegal water use. This however does not mean that high income neighborhoods do not consume water illegally, the cases maybe few and far between but the impact is just the same as those in high density areas, as stated in one of the reports of ADB, 2010 that the urban poor are normally blamed for illegal water consumption through theft however they do not have intensive appliances like the washing machine, or the need to tap water for the kitchen gardens and therefore the highest commercial losses through meter tampering and theft experienced by water utilities are from well-off residents and industrial users who usually use a lot of water. These findings also concur with a study from water and Sanitation for the urban poor (WSUP, 2018) which states that high density estates with numerous informal settlements there are gangs and cartels who take control of illegal water service provision by illegal and hard to trace connections due to the poor metering systems. Kingdom, Liemberger \& Marin (2006) and Hermann-Friede et al, 2011 indicated that illegal connections are major drivers of non-revenue water loss therefore improved meter readings and management can help uncover such illegal practices thereby reducing the level of nonrevenue water loss. At an FGD it was found that the high-density areas are usually neglected by KIWASCO and they take long to act when any cases are reported or if one gets their water disconnected therefore forcing one to use other means to access water or reconnect themselves to the main distribution system. Some of the discussants expressed concerns that KIWASCO staffs are overtly corrupt and therefore provide leeway for continued illegal connections by the consumers. According to the participants' corruption is an important aspect of illegal water consumption on the part of the water service providers that enhance illegal practices because a lot of people do favors to some meter readers and field agents from KIWASCO and make them overlook the basic regulations and requirements. The discussants also felt that most of the issues associated with illegal water use was due to the inefficiencies of KIWASCO especially in the informal settlements where most the consumers resort to illegal use as a form of rebellion against KIWASCO due to high tariff rates which they termed as being unfair. Kingdom, Liemberger \& Marin (2006) estimates that illegal water use can account for up to $40 \%$ of the water loss worldwide in water utilities. This observation indicates that despite there being other forms of water loss, this one is a serious problem that needs to addressed to ensure reduction in water loss worldwide.

\section{Summary of Research Findings}

The household survey was used to achieve the second objective which targeted 384 households but only 362 households participated in the survey. It was found that the level of illegal water consumption in higher and low density areas of Kisumu city significantly vary by $4.9 \%$ when it comes to illegal consumption through unmetered connections, water consumed through delayed water tariffs in Manyatta was 30.8\% and 26.1\% in Milimani, level of water disconnection was $8.1 \%$ higher in Manyatta than Milimani, on illegal reconnection however, the level of illegal consumption in Milimani was higher than that of Manyatta by $1.1 \%$ and finally illegal consumption through water meter irregularities was higher in Manyatta by $4.5 \%$.

\section{Conclusion}

In 4 out of the 5 illegal water determinants used by the researcher, illegal was found to be higher in the high density, low-income estate (Manyatta) and lower in low density, high income estate (Milimani) hence the conclusion that indeed there is a positive relationship between low income and increased levels of illegal consumption. It is however 
evident that the level of illegal consumption in both high- and low-density estates is higher than the recommended $25 \%$ of water loss by Water Services Regulatory Board of Kenya based on the five illegal water consumption determinants used by the researcher which were unmetered connection, delayed water tariffs, water disconnection, illegal reconnection and water meter irregularities.

\section{Recommendation}

Assumptions should not be made that there are no cases of illegal water use in low density areas if the water utility is to realize its goal of reducing non-revenue water loss to acceptable levels because these areas contribute to nonrevenue water loss just as much as the low-density areas as the number of illegal of use maybe low but the intensity may surpass that of high-density neighborhoods.

There is need to invest more in the installation of smart meters that are essential in mitigating illegal consumption and leak detectors that will help in significantly reducing the amount of water loss.

\section{References}

i. Alyse. S., and Katherine, W., Ingvar, A., Ben, G., 2015. Unsettled: Water and Sanitation in Urban Settlement Communities of the Pacific

ii. Arregui, F., Cabrera, E., Cobacho, R., Gacia-Serra, J., 2005. Key Factors Affecting Water Meter Accuracy, Leakage in 2005. Specialized conference of the IWA, Halifax, Canada, p. 10

iii. Baietti, A., Kingdom, W., van Ginneken, M., 2006. Characteristics of well-performing public Water utilities. World Bank Water Supply \& Sanitation Working. (Note 9). worldbank.org/INTWSS/Resources/Working note

iv. Bill balance and meter reading. MajiSMS (web), no year, Nairobi City Water and Sewerage Company, Kenya, accessed June 1, 2020,

v. Edison Electric Institute (EEI), Association of Edison Illuminating Companies (AEIC), Utilities Telecom Council (UTC), 2011. Smart meters and Smart meter systems. A metering industry perspective. USA

vi. Fanner, P., 2004. Assessing Real Losses, including Component Analysis and Economic Considerations: A Practical Approach. IWA Publishing, London, 21 (Article No 6). www.fondazioneamga.org/ public/fannerfe19maggio06.pdf

vii. Farley, M., Liemberger, R., 2004. Developing a non-revenue water reduction strategy: planning and implementing the strategy. 41-50.

viii. Farley, M., Wyeth, G., Ghazali, Z., Istandar, A., Singh, S., 2008. The Manager's Non-Revenue Water Handbook. A Guide to Understanding Water Losses. Ranhill Utilities Berhad and the United States Agency for International Development (USAID), Malaysia, 110.https://warrington.ufl.edu/centers/purc/docs/resources_NRWManagersHandbook.

ix. González-gómez, F., García-Rubio, M.A., Guardiola, J., García-Rubio, M.A., Guardiola, J., 2015. Why Is NonRevenue Water So High in So Many Cities? Why Is Non-Revenue Water So High in So Many Cities? International Journal of Water Resources Development, 27 (02): 345- 360.

X. Hailu, D., Sara R.S., and Raquel T., 2011. Small-Scale Water Providers in Kenya: Pioneers or Predators?

xi. Hope, F., Money, R., and Thomas. 2011. Smart Water Systems. Project report to UK DFID, Oxford University, UK

xii. IWA (International Water Association), 2008. Guidelines for the management of drinking water utilities under crisis conditions

xiii. Janek, H.F., Michael K., Sarah A., Johannes, H., Lotte, F., 2011. Integrity Management Toolbox for Water Service Providers Description of WSP Integrity Elekta anti-corruption policy.

xiv. Kazeeem, B.A, Yskandar, H., Bolanle T., Adnan M. Abu-Mahfouz. 2011. Leakage detection and estimation of algorithms for loss.

xv. Kingdom, B., Liemberger, R., Marin, P., 2006. Water Supply and Sanitation Sector Board Discussion Paper Series $\mathrm{s}$, The Challenge of Reducing Non-Revenue Water (NRW) in Developing Countries How the Private Sector Can Help: A Look at Performance-Based Service Contracting.

xvi. Lambert, A., 2003. Assessing non-revenue water and its components: a practical approach. Water 21, IWA Water Loss Task Force (June,): 50-51. www.fondazioneamga.it public/lambertfe19 maggio06.pdf

xvii. Leakage Management and Control - A Best Practice Training Manual, (C) 2001, WHO

xviii. Liu, W., Park, S., Bailey, R.T. et al. Quantifying the streamflow response to groundwater abstractions for irrigation or drinking water at catchment scale using SWAT and SWAT-MODFLOW. Environ Sci Eur 32, 113 (2020). https://doi.org/10.1186/s12302-020-00395-6

xix. LVSWSB Draft Strategic Plan, 2013-17, Kisumu, LVSWSB

xx. LVSWSB Newsletter (2012). Kisumu, LVSWSB.

xxi. Motiee, H., Motiei, A., Hejranfar, A., Reza, M., 2006. Assessment of Unaccounted-for Water in Municipal Water Networks Using GIS and Modeling. Journal of Water Management Modeling. 24, 547-558.

xxii. Mugabi, J., Kayaga, S., Njiru, C., 2007. Strategic planning for water utilities in developing countries, Utilities Policy. 15(1): 1-8

xxiii. Mutikanga, H.E., Sharma, S.K., Vairavamoorthy, K., 2011b. Investigating water meter performance in developing countries: A case study of Kampala, Uganda. Water and Environment Journal 37(4): 567-574.

xxiv. Sharma, S., 2008. Performance Indicators of Water Losses in Distribution System.

xxv. UDS Civil. 2017. Leak Detection and Water Loss Management

xxvi. Water and sanitation for the urban poor; A journey of institutional change 2015 
xxvii. WHO, 2000. Global Water Supply and Sanitation Assessment 2000 Report.

xxviii. WHO, 2003. Constraints Affecting the Development of the Water World Health Organization, Geneva. www.who.int/water_sanitation_health/en/righttowater.pdf

xxix. www.who.int/water_sanitation_health/monitoring/jmp2000.pdf

xxx. Wyatt, A. S. (2010). Non-Revenue Water: Financial Model for Optimal Management in Developing Countries. North Carolina: RTI International.

xxxi. Zaier, H. (2010). The management by the skills factor of performance and development in water companies. 3rd ACWUA Best Practices Conference (pp. 27-28). Morocco: UNW-DPC, Bonn, Germany.

xxxii. https://www.leakssuitelibrary.com/iwa-water-balance/ 